\title{
Efficacy of Sucralfate in Alleviating Pain And Morbidity in Post-Tonsillectomy Patients- A Randomized Control Trial
}

\author{
Diwaker Bista, Arun Alexander*, Surianarayanan Gopalakrishnan, Karthikeyan Ramasamy and Sivaraman \\ Ganesan \\ Department of ENT JIPMER, Pondicherry India
}

Submission: August 02, 2018; Published: August 07, 2018

*Corresponding author: Arun Alexander, Department of ENT, JIPMER, Pondicherry India, Tel:- +91-9445521580; Email: guyton2010@gmail.com

\section{Introduction}

Tonsillectomy is one of the commonest surgical procedures done in otolaryngology. Nonetheless, pain remains an important post-operative morbidity regarding patient well being as it may lead to secondary infection, bleeding and dehydration. Pain affects the oral intake of the child and thereby nourishment; leading to delayed wound healing, lack of wellbeing, prolonged hospital stay and financial burden both to the child and its parents.

Tonsillectomy leaves a raw surface at the tonsillar bed. The ensuing inflammation, irritation of the nerve endings and spasm of the pharyngeal muscles contribute to pain, trismus, and otalgia. Some authors have advocated that initiation of early pharyngeal activity (oral intake) to help decrease pain to a certain extent by overcoming the pharyngeal spasms [1]. Given the above morbidities associated with the surgery, adequate management of post-operative pain and other associated morbidities is important to every surgeon while performing a tonsillectomy. Several techniques in the past have been described both medical and surgical, to reducing post-operative pain and other morbidities with varying results, albeit with its limitations and controversies. The present study has been conducted keeping these very goals in mind and is an attempt to investigate the efficacy of Sucralfate in reducing the various a fore mentioned post-operative morbidities.

Sucralfate provides a physical barrier promoting mucosal healing in gastric and duodenal ulcers and has been in use for the same for considerable time. Since tonsillectomy leaves a raw surface where the above factors contribute to the genesis of pain, Sucralfate could well act to protect the raw mucosa and thereby alleviate the pain associated with it [2] Similarly, the tonsillar bed following tonsillectomy when coated with sucralfate heals faster and thus helps in early recovery. We have tried to study the efficacy of sucralfate in alleviating post-tonsillectomy pain and other morbidities like trismus, otalgia, fever and day of starting of oral intake. The present study is an aim to find a safe and cheap method to alleviate the sufferings of post-tonsillectomy paediatric patients.

\section{Aims and Objectives}

To Study the efficacy of Sucralfate in relieving postoperative pain and morbidity following tonsillectomy.

\section{Materials and Methods}

Subjects included in our study were patients admitted to the Department of ENT for tonsillectomy. The selection of patients was made using the following criteria.

\section{Inclusion Criteria}

a) Chronic Tonsillitis undergoing tonsillectomy.

b) Tonsillar hypertrophy that was obstructing respiration or deglutition.

c) Age group of $>6$ years

32. Exclusion Criteria

a) Patients not willing to stay for three days postoperatively.

b) Patients with bleeding disorders.

c) Type of study: Randomized control trial.

\section{Sample Size}

Sample size in each group and sample: 56 (28 in each group).

The sample size for randomized control trial was calculated using the proportion of patients who did not have severe pain to be $73 \%$ in the study group and $33 \%$ in the control group in a previous study by Freema [1]. The sample size was calculated with $\alpha=0.05$ and power=.80 using open Epi software. 
a) No of groups studied: two.

Group 1: patients receiving sucralfate postoperatively

Group 2: patients receiving placebo postoperatively

b) Drugs Used

i. Sucralfate $1 \mathrm{~g}$ in $50 \mathrm{ml}$ distilled water orally four times a day - study group.

ii. Glucose $1 \mathrm{~g}$ in $50 \mathrm{ml}$ distilled water - control group.

\section{Outcome Measures}

a) Throat pain

b) Trismus.

c) Otalgia

d) Fever

e) Bleeding

f) Diet intake

\subsection{Procedure}

The study was done following clearance from the Institute scientific committee and Ethical committees. Fifty-six patients in total were included in this study. All the patients were randomly allocated to study and control group with 28 in each group. Randomization was done using series of computer-generated random numbers. Allocation of each group was done was done using an opaque envelope method. For every patient, detailed history regarding the number of episodes of a sore throat due to tonsillitis, history of mouth breathing, any history of bleeding disorders, previous history of surgery, any significantly associated morbidities and family history was noted. Each patient to be included in the study was informed in detail about the procedure, and informed consent was obtained from all. The parents were explained to about the purpose of the study, need to stay for three days in the hospital and to follow up seven days post-operative period. All the surgeries were performed under general anaesthesia. A perioperative dose of ampicillin as per body weight was given at the time of induction of anaesthesia.

\section{Surgical Procedure}

All the surgeries were done using dissection and snare method. Intraoperative haemostasis was achieved by pressure and use of ligatures.

\section{Post-Operative Period}

Oral feeds were started six hours following extubation. Cold, bland diet was started, and child encouraged taking feeds actively. All patients were given oral Amoxicillin and paracetamol for seven days. From the first post-operative day patients in the study group were given 1 gram sucralfate dissolved in $50 \mathrm{ml}$ of distilled water four times daily. Patients were asked to swish and swallow the solution over a period of 4 to 5 minutes. The medication was given four times daily after meals and half an hour after gargling with diluted hydrogen peroxide and Listerine mouth wash which was also given four times a day. Patients in the control group were given glucose powder in distilled water and similarly asked to swish and swallow four times daily. Each patient was given a questionnaire and asked to evaluate the parameters every evening. The pain was assessed using a revised face pain scale for children.

\section{Results}

During the study, 56 of the patients of the patients undergoing tonsillectomy were randomly allocated into study group and control group. The mean age \pm SD among study group, was 10.36 \pm 2.392 and among control group was $10.89 \pm 3.224$. The males and females in the study group were 14 each. The control group had ten males comprising $35.7 \%$ while no of females were 18 comprising of $64.3 \%$ of the total number of participants in the study group. (P value 0.418).

\section{Throat Pain Score}

Table 1: Throat pain in each group.

\begin{tabular}{|c|c|c|c|}
\hline $\begin{array}{c}\text { Throat } \\
\text { pain }\end{array}$ & $\begin{array}{c}\text { No. in Sucralfate } \\
\text { Group } \\
\text { Median } \\
\text { (Interquartile range) }\end{array}$ & $\begin{array}{l}\text { No. in Control } \\
\text { Group } \\
\text { Median } \\
\text { (Interquartile } \\
\text { range) }\end{array}$ & $P$ value* \\
\hline $\begin{array}{c}\text { Post op } \\
\text { day } 1\end{array}$ & 8 (6 to 8$)$ & 8 (8 to 10$)$ & 0.147 \\
\hline $\begin{array}{c}\text { Post op } \\
\text { day } 2\end{array}$ & 6 (4 to 8$)$ & 8 (6 to 8$)$ & 0.001 \\
\hline $\begin{array}{c}\text { Post op } \\
\text { day } 3\end{array}$ & $4(2$ to 4$)$ & 6 (4 to 7.5$)$ & 0.000 \\
\hline $\begin{array}{c}\text { Post op } \\
\text { day } 7\end{array}$ & $0(0$ to 2$)$ & 1 (0to 3.5) & 0.000 \\
\hline
\end{tabular}

${ }^{*}$ p-value calculated using Mann-Whitney U Test.

Pain score was measured on postoperative day 1, 2, 3 and 7 (Table 1). As pain score was not normally distributed, the median score was compared between the two groups and $P$ value calculated using Mann-Whitney U test. The median (IQR) of pain score on postoperative day 1 was found to be 8 (6to8) in the study group and 8(8to10) in the control group. The difference in pain score between the two groups on postoperative day 1 was not found to be statistically significant with p-value 0.147 $(>0.05)$. The median (IQR) of pain score on postoperative day 2 was found to be 6 (6to8) in the study group and 8(6to8) in the control group. The difference in pain score between the two groups on postoperative day 2 was found to be statistically significant with $\mathrm{p}$-value $0.001(<0.05)$. On postoperative day 3 , median (IQR) pain score was found to be 4 (2to4) in the study group and 6(4to7.5) in the control group and the difference was found to be statistically significant with $p$ value $<0.05$ ). On Postoperative day, 7 Sucralfate group continued to have a lower pain score 0 (0 to 2) compared to control sucralfate (0to 6). Thus, the benefit of Sucralfate on throat pain started on the second postoperative day till the seventh. 


\section{Global Journal of Otolaryngology}

\section{Otalgia}

Table 2: Otalgia in each group.

\begin{tabular}{|c|c|c|c|c|}
\hline & Otalgia & $\begin{array}{c}\text { Sucralfate } \\
\text { Group } \\
\text { N (\%) }\end{array}$ & $\begin{array}{c}\text { Control } \\
\text { Group } \\
\text { N (\%) }\end{array}$ & \multirow{2}{*}{ P value } \\
\hline \multirow{2}{*}{$\begin{array}{c}\text { Post op } \\
\text { day 1 }\end{array}$} & Present & $12(42.9)$ & $18(64.3)$ & \multirow{2}{*}{0.18} \\
\cline { 2 - 4 } & Absent & $16(57.1)$ & $10(35.7)$ & \\
\hline \multirow{2}{*}{$\begin{array}{c}\text { Post op } \\
\text { day 2 }\end{array}$} & Present & $4(14.3)$ & $12(42.9)$ & \multirow{2}{*}{0.04} \\
\cline { 2 - 4 } & Absent & $24(85.7)$ & $16(57.1)$ & \\
\hline \multirow{2}{*}{$\begin{array}{c}\text { Post op } \\
\text { day 3 }\end{array}$} & Present & $0(0.00)$ & $14(50.0)$ & \multirow{2}{*}{0.00} \\
\cline { 2 - 4 } & Absent & $28(100.0)$ & $14(50.0)$ & \multirow{2}{*}{0.00} \\
\hline \multirow{2}{*}{$\begin{array}{c}\text { Post op } \\
\text { day 7 }\end{array}$} & Present & $0(0.00)$ & $13(46.4)$ & \\
\cline { 2 - 4 } & Absent & $28(100.0)$ & $15(53.6)$ & \multicolumn{2}{|c|}{} \\
\hline
\end{tabular}

${ }^{*} p$ value calculated by using chi-square test.

On the first post-operative day, 12 patients in the study group complained of ear pain while in the control group, 18 patients had ear pain (Table 2). Among the sucralfate group, $42.9 \%$ had ear pain while $57.1 \%$ didn't complain of otalgia. In the control group $64.3 \%$ had otalgia while $35.7 \%$ did not. The difference in the incidence of otalgia between the two groups was not statistically significant (P 0.18). By the evening of the second day, onwards 12 (42.9\%) patients of the control group had otalgia compared to just $4(14.3 \%)$ patients in the sucralfate group, making it significantly lower in the Sucralfate group (P 0.04). The effect of sucralfate in decreasing ear ache persisted in post-operative day 3 and day 7 with the difference in otalgia, statistically significant in the study group compared to control group. On day 3, 14 (50\%) patients in the control group had ear pain while none of them in Sucralfate group had ear pain. By 7th post-operative day 13 patients (46.4\%) had otalgia while none in the sucralfate group had any pain. Thus, Sucralfate was found to be effective in preventing otalgia from second post-operative day onwards.

\section{Trismus}

The number of patients having trismus in the Sucralfate group (53.6\%) and control group (64.3\%) were similar during the first post-operative day. A significant difference of trismus between the two groups was apparent only by second day onwards were 15 (53.6\%) out of 28 patients in the control group had trismus while only $5(17.9 \%)$ out of 28 patients in the study group had trismus. (P value 0.01). In third post-operative day 3 , only one patient in the Sucralfate group had trismus compared to 2 patients in the control group while one day 7 , only one patient in the Sucralfate group had trismus. Thus apart from day two post op, rest of the days the difference between the two groups was not found to be statistically significant and overall the number of both the groups was not clinically significant.

\section{Fever}

There was no significant difference in the incidence of pyrexia among both the groups on all evaluated postoperative days. On day one, four patients in Sucralfate group while 3 in the control group had a fever. On day two and day three only one patient among the Sucralfate group had temperature recording more than $98.4 \mathrm{oF}$. By day seven none of the patients had evidence of any febrile episodes.

\section{Bleeding}

There was no patient with postoperative bleeding in either group.

\section{Diet Intake}

The median day (IQR) of starting $50 \%$ of diet intake in Sucralfate group was 2(2to3) days compared to 3(2to3) days in the control group. Most of the patients in the Sucralfate group reverted to $50 \%$ of their diet intake by the second day $(57.14 \%)$ compared to $32.14 \%$ patients in the control group. Though all the patients in both the groups took $50 \%$ of their diet by the third day, major bulk of patients were from the control group (67.85\%) while only $32.14 \%$ of patients from Sucralfate group as rest of them had taken normal diet on the second day itself.

\section{Discussion}

Tonsillectomy, as with any surgical procedure is associated with various post-surgical morbidities. Pain among them is the most worrisome problem both for the child and their parents. Sucralfate is sulfated disaccharide sucrose complexed with Aluminium hydroxide. It is water insoluble synthetic compound and hence can form an adequate coating over the tonsillar bed. The ulcer protective effect of Sucralfate is attributed to its ability to perform a complex with proteins that adhere to the raw surface [3]. We felt that sucralfate would form a chemical barrier over the exposed raw bed and prevent stimulation of nerve endings thereby alleviating pain. Healing and epithelization are also promoted as Sucralfate has been shown to have a cytoprotective effect [4] Thus, it creates a local environment for faster healing to occur.

\section{Throat Pain}

Pain assessment in children was done using revised face pain scale. Revised face pain scale consists of a set of a photograph of faces portraying various states of pain along with numerical value attached alongside [2]. Face pain scale is easily understood by younger patients and has been recommended for children six years and older. [5] It has an additional advantage that it is suitable for use with the metric system of scoring (0-10) and a correlation with numerical value was highly consistent. Its validity also was supported by the fact that it showed a positive correlation with the well-known visual analogue scale. Pain scores were measured on a post-operative day one in the evening 
of each day. Sucralfate topically was also started from day one. There was no significant difference in the pain score between the two groups on the first postoperative day, and the median pain score among both the groups was 8 . This observation was like that observed by Freeman et al. who reported significant pain relief only on the second postoperative day [1]. The pain intensity among patients receiving sucralfate had a median (IQR) value of 6 (4 to 8) compared to control group who had median (IQR) pain score of 8 (6 to 8) on day two post-surgery. Siupsinkien also observed the apparent effect on the second day only in the Sucralfate group compared to control group [6]. This could be due to the time is taken by Sucralfate in forming an effective chemical barrier. Since we had started the drug from the morning of post-operative day one, this could explain the lack of difference seen in the first post-operative day (although this was not the case with previous studies).

It was felt that child who would remain drowsy under the effect of anaesthesia and because of oedema and inflammation, compliance in using the agent was doubted. The benefits of Sucralfate in our study also started becoming apparent by second postoperative day continuing to seven days. There was a significant reduction in the pain score among both the groups as the number of the post-operative days increased. This is part of the natural history of the disease that with healing, the pain will decrease. The difference between the groups persisted until their follow up on the seventh post-operative day with patients in sucralfate complaining of less pain compared to control group. Freeman et all had followed up patients for ten days, so he had reported pain difference between the two groups even up to ten postoperative days [1] Authors who had used Dexamethasone and ropivacaine infiltration reported pain relief on post-operative day one itself [7]. Similarly, Kaan MN who had used preoperative dexamethasone claimed patients who received preoperative Dexamethasone having less pain score during the first 6 hours postoperatively itself [8]. These early benefit so claimed possibly reflects the mechanisms of action of the agents used. Sucralfate doesn't have any analgesic property, so its immediate effect may not be apparent. Miura et al. however who started using Sucralfate from the intraoperative period continuing in the post-operative period reported benefits from the first post-operative day itself [2] Sampaio reported a significant reduction in pain scores in the sucralfate group only in the initial six hours post-operatively and no difference after that. He had therefore concluded that Sucralfate may not be effective in reducing post-surgery morbidity [9]. It is to be noted that standard doses of analgesics were given to all patients in both the groups. Though we have observed Sucralfate effective in reducing post-operative pain in the study group, our aim was not to replace it as the sole analgesic agent. Our study assumes significance in the light of Sucralfate being a cheap and safe addon therapy for relief of pain in the paediatric group as it was well tolerated by all patients.

\section{Fever}

There was no significant difference in the episodes of fever among the two groups in our study. This observation is consistent to that observed by Freeman at al where no difference was found in this parameter between the two groups [1]. Fever is a sign of infection, and since we had administered antibiotics preoperatively and continued in the postoperative period, this could explain the absence of pyrexia in both the groups. Dhiwakar also reported that antibiotics reduced the proportion of fever among post-tonsillectomy patients (P 0.002) [10]. Telian though didn't measure febrile episodes as an outcome parameter in their study; they found antibiotic usage associated with decreased halitosis in the treatment group compared to placebo [11] Halitosis can be regarded as an indirect evidence of infection. Grandis et al. also found patients on antibiotics had less mouth odour compared to those on placebo reflecting the role of antibiotics in preventing infection [12].

\section{Bleeding}

No bleeding was observed in any of the patients in both the groups during the entire evaluation period. Freeman et al. had reported the mean of 1.94 episodes of bleeding in the placebo group compared to 1.69 episodes of bleeding in the sucralfate though this was not statistically significant. [1] Esteban also didn't notice any increase in bleeding in the Sucralfate group. [13] Miura using sucralfate found only a reduction in pain whereas secondary parameters like bleeding, otalgia, fever, weight loss and vomiting were largely unaffected. [5] Sucralfate doesn't have any effect on the haemostatic mechanisms of our body henceforth it doesn't affect bleeding. We did not notice any episodes of reactionary or secondary haemorrhage in any of the patients in either of study group or control group. In the past several authors reported an increase in the incidence of post-operative bleeding with use of other agents like steroids. Suzuki cautioned the use of intravenous dexamethasone on the day of surgery as an independent risk factor for bleeding in the postoperative period. We deferred from the utilization of any form of steroids for our patients both in intraoperative or in the post-operative period. However given the small sample size of our study and the relatively less incidence of postoperative bleeding, in general, we are unable to conclude safely on the increased risk of haemorrhage due to the use of Sucralfate.

\section{Otalgia}

Otalgia is a referred pain; this occurs due to irritation of nerve endings in the bare tonsillar fossa. Referred otalgia was significantly more in the placebo group as compared to the study group. We observed that compared to 12 patients $(42.9 \%)$ in the sucralfate group had otalgia, 18 patients $(64.3 \%)$ in the control group had otalgia. This appears to be clinically significant however this difference was not found to be statistically significant. The smaller sample size could be a reason for this discrepancy. By the second day, however, beneficial effects 
of Sucralfate was apparent with only four patients $(14.3 \%)$ in the Sucralfate group while 12 patients (42.9\%) in the control group had ear pain. The beneficial effect of sucralfate lasted till the end of follow-up period of seven days. Freeman et al. though observed this beneficial effects of Sucralfate, it was significant only on the fifth post-operative day which then remained significant after that during their entire follow-up period [1]. Miura didn't observe any difference in otalgia between the two groups [5]. Sampaio also didn't report a reduction in otalgia in the sucralfate group [9].

\section{Trismus}

The lower level of pain observed with Sucralfate from the second postoperative day was reflected in the measurement of trismus also. The difference was apparent in the second postoperative day. By third and seventh postoperative day both groups had a reduction in trismus with just one patient in the Sucralfate group having it on the third day. We found a sudden decrease of trismus recorded on the third day compared to the second day. Trismus was thus more apparent with the control group. This was possible because we recorded trismus as either present or absent rather than measuring its grade. So mild degrees of trismus must have been erroneously reported as being absent and only the severe ones being recorded as being present. Freeman at al recorded the average level of improvement in trismus by day 5 in the Sucralfate group compared to 9 days in the control group [1]. Many of the other studies on Sucralfate haven't used trismus as outcome measure except Freeman et al so we couldn't compare our observation concerning this parameter to the rest [1].

\section{Diet Intake}

Diet as an indicator of morbidity has been mentioned in few of previous studies. Early intake of diet post tonsillectomy is encouraged not just because nutrition is important for healing process but chewing movements help overcome muscle spasms, pain, the incidence of bleeding, etc. Early resumption of normal diet also allays fear of apprehensive parents to some extent. The day of resumption of $50 \%$ of solid diet was compared among patient groups. The measurement of $50 \%$ of diet intake was based on information provided by the parents/ attendee of the patient who were assumed to know the normal dietary intake of the child. Thus, it was a purely subjective basis of evaluation. We observed that the day of initiation of $50 \%$ of normal diet intake was faster in sucralfate group compared to the placebo group. $57.14 \%$ took $50 \%$ of their normal diet on the second day compared to $32.14 \%$ in the control group. This is in coherence with the better reduction of pain and trismus provided by Sucralfate. The pilot trial on Sucralfate had reported all patients in Sucralfate group were able to eat $50 \%$ of their diet by the sixth day while those in the control group by eighth day only [1] In our study by the end of the third day all the patients in both the groups were able to take $50 \%$ of their diet intake Most studies done previously also had a positive impact on the diet intake of the recovering patient [1] The latest study on this subject by Siupsinskiene N in 2015, however, didn't evaluate diet intake as an outcome parameter [6].

\section{Conclusion}

Sucralfate is a useful adjuvant in the management of children following tonsillectomy as it significantly reduces postoperative pain and allows for the early resumption of oral feeding when compared to placebo. Sucralfate was also found to have no increase in the incidence of post-operative bleeding when compared with placebo.

\section{References}

1. Freeman SB, Markwell JK (1992) Sucralfate in alleviating posttonsillectomy pain. Laryngoscope 102(11): 1242-1246.

2. Vaiman M, Krakovski D, Haitov Z (2011) Oxycodone and dexamethasone for pain management after tonsillectomy: a placebocontrolled EMG assessed clinical trial. Med Sci Monit 17(10): I25-131.

3. Jácomo AL, Akamatsu FE, Andrade M, Margarido NF (2010) Pharyngeal lymphatic ring: anatomical review. J Morphol Sci 27(1): 47-49.

4. Maria Piagkou SA (2009) Eagle's Syndrome: A review of the literature. Clinical anatomy, New York, NY 22(5): 545-558.

5. Oghan F, Harputluoglu U, Guclu E, Kocaman B, Ozturk O (2008) Does topical ropivacaine reduce the post-tonsillectomy morbidity in pediatric patients?. Int J Pediatr Otorhinolaryngol 72(3): 361-365.

6. B Viswanatha (2015) Tonsil, Adenoid Anatomy: Overview, Gross Anatomy, Microscopic Anatomy.

7. Rees WD (1991) Mechanisms of gastroduodenal protection by sucralfate. Am J Med 91(2): 58S-63S.

8. Miura MS, Saleh C, De Andrade M, Assmann M, Ayres M, et al. (2009) Topical sucralfate in post-adenotonsillectomy analgesia in children: a double-blind randomized clinical trial. Otolaryngol Head Neck Surg 141(3): 322-328.

9. Siupsinskiene N, Žekonienė J, Padervinskis E, Žekonis G, Vaitkus S (2015) Efficacy of sucralfate for the treatment of post-tonsillectomy symptoms. Eur Arch Otorhinolaryngol 272(2): 271-278.

10. Erdogan BA, Aydin S, Paksoy M, Sanli A, Sevim S (2014) Efficacy of preincisional levobupivacaine for adult tonsillectomy patients. B-ENT 10(3): 193-197.

11. Kasapoglu F, Demir UL, Kaya FN, Cetin YS, Yavascaoglu B, et al. (2013) The effects of levobupivacaine infiltration on post-tonsillectomy pain relief in adults: a single-blinded, randomized, and controlled clinical study. Eur Arch Otorhinolaryngol 270(2): 761-766.

12. Melchor MA, Villafruela MA, Muñoz B, Domingo C, Ontañón M, et al. (1994) Postoperative pain in tonsillectomy in general anesthesia and local infiltration. Acta Otorrinolaringol Esp 45(5): 349-355.

13. Ozkiriș M, Kapusuz Z, Saydam L (2012) Comparison of ropivacaine, bupivacaine and lidocaine in the management of post-tonsillectomy pain. Int J Pediatr Otorhinolaryngol 76(12): 1831-1834. 
(C) This work is licensed under Creative BY DOI: 10.19080/GJO.2018.17.555957
Your next submission with Juniper Publishers will reach you the below assets

- Quality Editorial service

- Swift Peer Review

- Reprints availability

- E-prints Service

- Manuscript Podcast for convenient understanding

- Global attainment for your research

- Manuscript accessibility in different formats

( Pdf, E-pub, Full Text, Audio)

- Unceasing customer service

Track the below URL for one-step submission https://juniperpublishers.com/online-submission.php 